\title{
3-M syndrome: a novel CUL7 mutation associated with respiratory distress and a good response to GH therapy
}

\author{
A Deeb, O Afandi', S Attia and A El Fatih ${ }^{2}$ \\ Paediatric Endocrinology Department, Mafraq Hospital, PO Box 2951 Abu Dhabi, United Arab Emirates \\ ${ }^{1}$ Medical School, Gulf University, Ajman, United Arab Emirates ${ }^{2}$ Biochemistry Laboratory Department, \\ Shaikh Khalifa Medical Center, Mafraq Hospital, Abu Dhabi, United Arab Emirates
}

Correspondence should be addressed to A Deeb

Email

adeeb@mafraqhospital.ae

\section{Summary}

3-M syndrome is a rare autosomal recessive disorder caused by mutations in the CUL7, OBSL1 and CCDC8 genes. It is characterised by growth failure, dysmorphic features and skeletal abnormalities. Data in the literature show variable efficacy of GH in the treatment of short stature. We report four Emirati siblings with the condition. The index case is a 10-year-old boy with characteristic features, including prenatal and postnatal growth failure, a triangular face, a long philtrum, full lips and prominent heels. Genetic testing confirmed a novel mutation (p.val88Ala) in the CUL7 gene. The parents are healthy, first-degree cousins with nine children, of whom two died in the first year of life with respiratory failure. Both had low birth weight and growth retardation. The boy's older sibling reached an adult height of $117 \mathrm{~cm}(-6.71 \mathrm{SDS})$. She was never treated with GH. He was started on GH treatment at 7 years of age, when his height was $94 \mathrm{~cm}$ ( $-5.3 \mathrm{SDS})$. 3-M syndrome should be considered in children with short stature who have associated dysmorphism and skeletal abnormalities. The diagnosis is more likely to occur in families that have a history of consanguinity and more than one affected sibling. Death in early infancy due to respiratory failure is another clue to the diagnosis, which might have a variable phenotype within a family. Genetic testing is important for confirming the diagnosis and for genetic counselling. GH treatment might be beneficial in improving stature in affected children.

\section{Learning points:}

- 3-M syndrome should be considered in families that have more than one sibling with short stature, particularly if there is consanguinity.

- Syndrome phenotype might be variable within a family with the same mutation.

- Genetic analysis is helpful in confirming diagnosis in the presence of variable siblings' phenotype.

- GH treatment might be useful in improving stature in 3-M syndrome.

\section{Background}

3-M syndrome is an autosomal recessive disorder that was initially described by Miller et al. (1), hence the name 3-M. The syndrome is characterised by dysmorphic features, skeletal abnormalities, severe prenatal and postnatal growth retardation and normal intelligence. The features can be subtle and difficult to differentiate from other types of dwarfism, which raises the possibility that the syndrome could be underdiagnosed (2). In particular, the syndrome resembles Silver Russel syndrome, in that the two syndromes have similar achievements in adult height (3). However, since the early description of 3-M syndrome, features that differentiate it from Silver Russel syndrome have been described (4). Classical clinical features of 3-M syndrome include a triangular face with a pointed chin, a long 


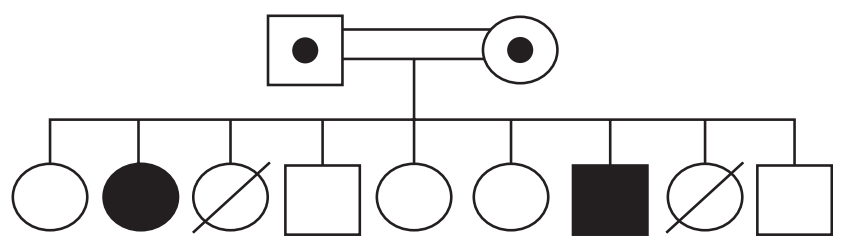

Figure 1

Family pedigree showing affected siblings. Carrier status in both parents is indicated by a small closed circle inside the circle and square.

philtrum and full lips. Skeletal features include hyperlordosis, short digits, prominent heels, winged scapulae, pes planus and joint hypermobility and dislocation (5). Classical radiological features include typical slender long bones and foreshortened vertebral bodies.

The genetic defect in this syndrome has three variants: 3-M1, 3-M2 and 3-M3. The three forms are caused by mutations in the CUL7 gene at location 6p21.1, the OBSL1 gene at $2 \mathrm{q} 35$ and the $C C D C 8$ gene at $19 \mathrm{q} 13.32$ respectively. Huber et al. (6) reported 25 distinct mutations in the CUL7 gene in 29 families with 3-M syndrome. In 2009, 19 novel mutations throughout the CUL7 gene were identified (7).

\section{Case presentation}

We report a family of four siblings with variable clinical features of 3-M syndrome. They were born to healthy, firstdegree relative parents who were of normal height. The parents had nine children, of whom two died in the first year of life with respiratory failure (Fig. 1). A distant relative from the maternal side had three affected children, two of which also died during infancy with respiratory failure. All four affected siblings had low birth weight and growth retardation. The index case is a 10 -year-old boy who was referred with short stature at the age of 7 years. He was born at term and had a birth weight of $2.0 \mathrm{~kg}$. Antenatally, he was suspected to have skeletal dysplasia. He has classical clinical features of 3-M syndrome: a triangular face with pointy chin, large head circumference, a prominent forehead, a long philtrum, a fleshy nose, short digits, hyper-extendable thumbs, prominent heels and marked lordosis (Fig. 2A, B and C). His height on presentation was $94 \mathrm{~cm}(-5.3 \mathrm{SDS})$.

Two of his sisters died in infancy at 9 and 12 months of age. Both were born small for their gestational ages and were diagnosed with a nonspecific form of skeletal dysplasia after birth. They had short chests, and one had a triangular face. Both failed to thrive and suffered recurrent respiratory tract infections that required repeated hospital admissions. The younger sibling required ventilation for bronchiolitis, which led to death, while the other died following pneumonia. Her chest X-ray showed a narrow thoracic cage in addition to features of lung collapse.

\section{Investigation}

The index patient's bone age showed a 2-year delay. His growth hormone $(\mathrm{GH})$ peak on a glucagon stimulation test was $9.6 \mu \mathrm{g} / \mathrm{l}$ (cut off: $10 \mu \mathrm{g} / \mathrm{l}$ ). His insulin-like growth factor1 (IGF1) level was normal at $13.28 \mathrm{nmol}$ (NR: 7.8-51.8), as was his IGF-binding protein 3 (IGFBP3) at $117 \mathrm{nmol}$ (55.6-292). His thyroid function tests were normal, and his celiac screen was negative. He exhibited foreshortening of the vertebrae and slender tibiae radiologically.

\section{Genetic testing}

All coding exons and the adjacent introns of CUL7 were sequenced in the index patient, his older sibling and his parents. A deletion of the nucleotide thyamine at the position c.263 was detected (c.263delT) in exon 2, leading to premature translation stop (p.val88Ala). The reference sequence for the mutation was NM_014780.4. Both the index case and his sister were homozygous to this mutation, and both parents are heterozygous carriers.
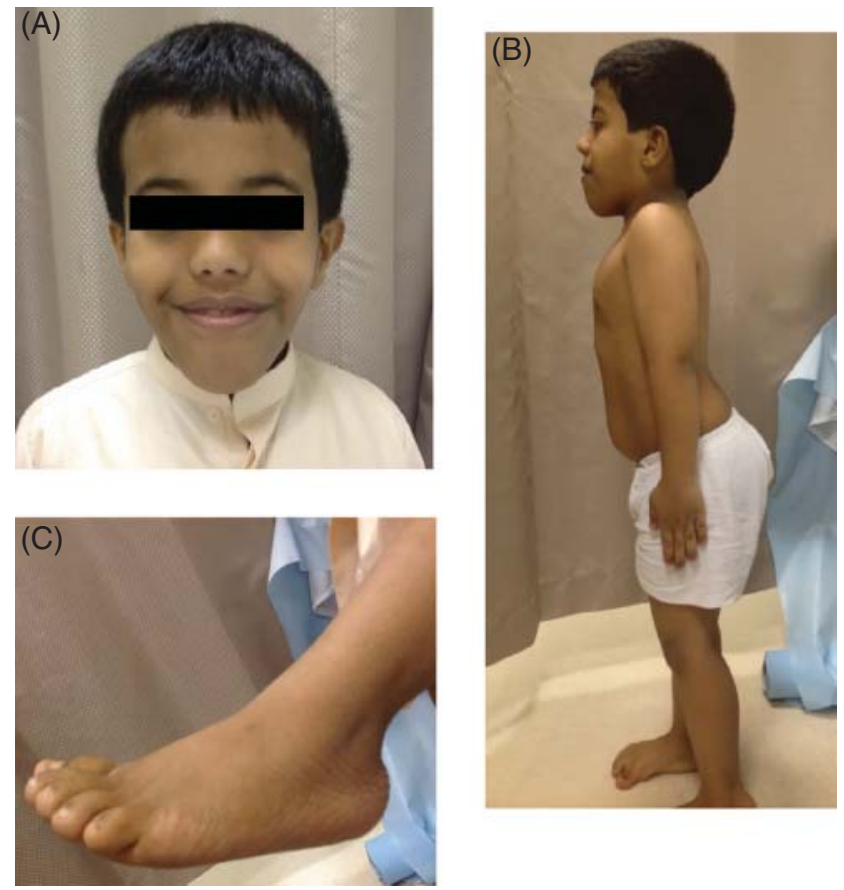

Figure 2

Photo of the face of the index case showing (A) his triangular face, upturned nose and full lips, (B) lordosis and (C) the prominent heel of his foot. 


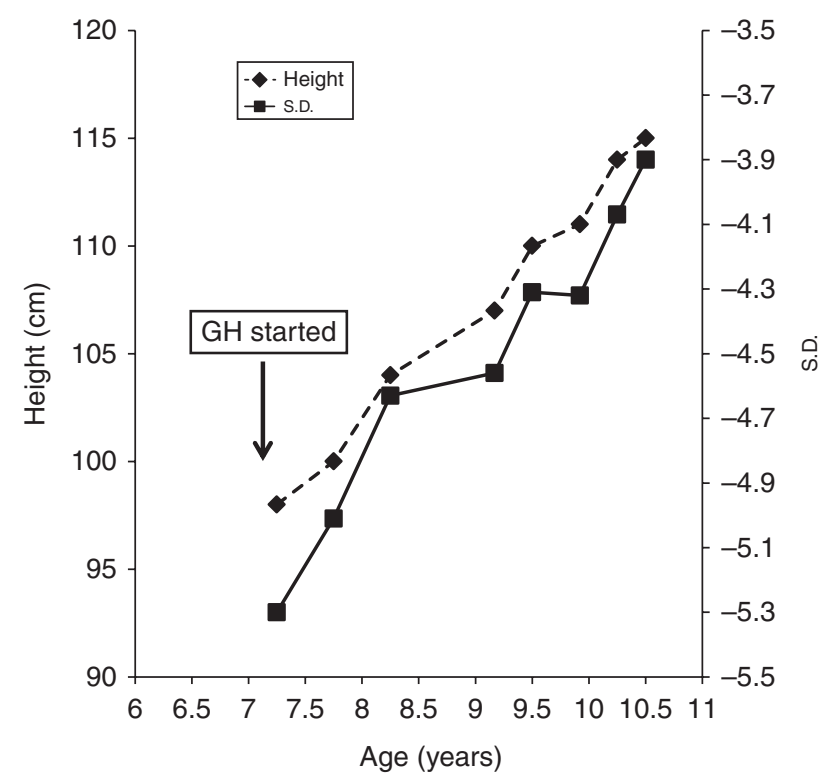

Figure 3

Line chart showing height and height SDS. Start of growth hormone (GH) treatment is indicated on the graph.

\section{Treatment}

The index patient was started on $\mathrm{GH}$ at a dose of $0.045 \mathrm{mg} / \mathrm{kg}$ per day.

\section{Outcome and follow-up}

At the start of GH treatment at 7 years of age, the index patient's height was $94 \mathrm{~cm}(-5.3 \mathrm{SDS})$. In the first year, growth velocity was noted to be $8 \mathrm{~cm} /$ year. By the age of 10.3, his height was $115 \mathrm{~cm}$ (-3.9 SDS). His growth velocity over the second and third years of treatment was $6.5 \mathrm{~cm} /$ year (Fig. 3). Pubertal assessment at the age of 10.5 years revealed a pre-pubertal status, with pubic hair stage PHI, genitalia GI and testicular size of $3 \mathrm{ml}$ bilaterally.

The older sibling reached an adult height of $117 \mathrm{~cm}$ $(-7.04$ SDS). She has never received GH treatment.

\section{Discussion}

3-M syndrome is a heterogeneous syndrome with variable severity. Some affected children die early in life as a result of respiratory distress. Maksimova et al. (8) identified 43 patients from 37 Yakut families with 3-M syndrome. Approximately $42 \%$ of them had severe asphyxia and respiratory distress at birth. In five of the families, affected newborns died shortly after birth from unknown causes. In addition to the short, wide thoraces seen in the affected babies, lung histology showed poor development of the cartilagenous lamina of the bronchi (8). Others had short stature and variable degrees of dysmorphic features but no major ill health. In the present family, there is a major phenotype difference in the four affected siblings. While two siblings died during infancy with thoracic asphyxiating syndrome and respiratory failure, the other two siblings showed no adverse respiratory features. Growth has also been different in the siblings. All four were born small for their gestational ages. The oldest sibling was severely short, with an adult height of $117 \mathrm{~cm}(-7.05$ SDS), whereas her younger sibling grew to $94 \mathrm{~cm}$ by the age of 7 years ( -5.0 SDS), and that height has improved to -3.9 SDS after 3 years of GH treatment. The use of recombinant human GH (rhGH) for the treatment of short stature associated with 3-M syndrome has been described in the literature. Data suggest a degree of GH resistance (9) and, in others, GH deficiency (9) (10). The present index case has shown improvement on GH treatment that could be attributed to his partial GH deficiency status. It is also reported that the 3-M syndrome is associated with dysregulation of GH, IGF1 and IGF binding protein (11). The present index case had normal IGF1 and IGFBP3 levels. Significant individual variation is reported in relation to $\mathrm{GH}$ response. Some references showed a benefit of treatment (3), while others proved the contrary (12). Variable response to GH based on the genotype has been reported, with a better response noted in patients that have a CCDC 8 mutation as compared to an OBSL1mutation (9). The present family had a mutation in the CUL7 gene, and that mutation could explain why the index case exhibited some response to GH.

CUL7 appears to be the major gene responsible in $\sim 77 \%$ cases, while OBSL1 mutations account for $16 \%$ (13). The present family had a novel mutation in exon $2 \mathrm{~A}$, with a deletion of the nucleotide thyamine at the position c.263. The deleted nucleotide resulted in a premature stop codon and nonsense-mediated decay, which produced the abnormal protein.

The heterogeneity of phenotype in the siblings was marked. The exact cause for this variation is unclear. However, it is possible that factors such as epigenetic variation or intrauterine stress may be confounders. In addition, there is a possibility that there was an additional mutation or modifier gene in the two siblings who died during infancy. However, genetic testing was not performed on them.

\section{Conclusion}

3-M syndrome should be considered in patients that present with prenatal and postnatal growth failure. This is 
particularly important in the presence of more than one affected child and when it is associated with specific dysmorphic and skeletal features. Intra-familial phenotype variation might be seen with variable degrees of severity in terms of compatibility with life and degree of growth failure. In view of the variation of response to $\mathrm{GH}$, a trial of rhGH treatment should be considered. Genetic diagnosis for the syndrome enables appropriate genetic counselling in this recessive condition.

\section{Declaration of interest}

The authors declare that there is no conflict of interest that could be perceived as prejudicing the impartiality of the research reported.

\section{Funding}

This research did not receive any specific grant from any funding agency in the public, commercial or not-for-profit sector.

\section{Patient consent}

Informed consent was obtained from the mother of the patient for the publication of the submitted article and its accompanying images.

\section{Author contribution statement}

A Deeb was the patients' clinician, ran the investigations and prescribed the treatment, wrote the manuscript, liaised between the authors and submitted the manuscript; O Afandi contributed to the literature search, obtained the images and drew the graph; S Attia participated in the literature search, helped in patient follow-up and obtained the details of the treatment outcome; A E Fatih advised on the biochemistry results and reviewed the manuscript for submission.

\section{References}

1 Miller JD, McKusick VA, Malvaux P, Temtamy SA \& Salinas CF 1975 The 3-M syndrome: a heritable low birthweight dwarfism. Birth Defects Original Article Series 5 39-47.
2 Al-Dosari MS, Al-Shammari M, Shaheen R, Faqeih E, Alghofely MA, Boukai A \& Alkuraya FS 2012 3-M syndrome: an easily recognizable yet underdiagnosed cause of proportionate short stature. Journal of Pediatrics 161 139-145. (doi:10.1016/j.jpeds.2011.12.051)

3 van der Wala G, Ottenb BJ, Brunnera HG \& van der Burgta I 2001 3-M syndrome: description of six new patients with review of the literature. Clinical Dysmorphology 10 241-252. (doi:10.1097/00019605200110000-00002)

4 Spranger JW, Opitz JM \& Nourmand A 1976 A new familial intrauterine growth retardation syndrome: the 3-M syndrome. European Journal of Pediatrics 123 115-124. (doi:10.1007/BF00442641)

5 Temtamy SA, Aglan MS, Ashour AM, Ramzy MI, Hosny LA \& Mostafa MI 2006 3-M syndrome: a report of three Egyptian cases with review of the literature. Clinical Dysmorphology 15 55-64. (doi:10.1097/01.mcd. 0000198926.01706.33)

6 Huber C, Dias-Santagata D, Glaser A, O'Sullivan J, Brauner R, Wu K, Xu X, Pearce K, Wang R, Giovannucci Uzielli ML et al 2005 Identification of mutations in CUL7 in 3-M syndrome. Nature Genetics 37 1119-1124. (doi:10.1038/ng1628)

7 Huber C, Delezoide A-L, Guimiot F, Baumann C, Malan V, Le Merrer M, Da Silva DB, Bonneau D, Chatelain P, Chu C et al 2009 A large-scale mutation search reveals genetic heterogeneity in 3-M syndrome. European Journal of Human Genetics 17 395-400. (doi:10.1038/ejhg.2008.200)

8 Maksimova N, Hara K, Miyashia A, Nikolaeva I, Shiga A, Nogovicina A, Sukhomyasova A, Argunov V, Shvedova A, Ikeuchi T et al 2007 Clinical, molecular and histopathological features of short stature syndrome with novel CUL7 mutation in Yakuts: new population isolate in Asia. Journal of Medical Genetics 44 772-778. (doi:10.1136/jmg.2007.051979)

9 Clayton PE, Hanson D, Magee L, Murray PG, Saunders E, Abu-Amero SN, Gudrun E, Graeme C \& Black M 2012 Exploring the spectrum of 3-M syndrome, a primordial short stature disorder of disrupted ubiquitination. Clinical Endocrinology 77 335-342. (doi:10.1111/j.13652265.2012.04428.x)

10 Meazza C, Lausch E, Pagani S, Bozzola E, Calcaterra V, Superti-Furga A, Silengo M \& Bozzola M 2013 3-M syndrome associated with growth hormone deficiency: 18 year follow-up of a patient. Italian Journal of Pediatrics 21 21. (doi:10.1186/1824-7288-39-21)

11 Hanson D, Murray PG, Coulson T, Sud A, Omokanye A, Stratta E \& Sakhinia F 2012 Mutations in CUL7, OBSL1 and CCDC8 in 3-M syndrome lead to disordered growth factor signaling. Journal of Molecular Endocrinology 49 267-275. (doi:10.1530/JME-12-0034)

12 Güven A \& Nurcan Cebeci A 2011 3-M syndrome: a report of four cases in two families. Journal of Clinical Research in Pediatric Endocrinology $\mathbf{3}$ 154-159. (doi:10.4274/jcrpe.v3i3.30)

13 Huber C, Munnich A \& Cormier-Daire V 2011 3-M syndrome. Best Practice \& Research. Clinical Endocrinology \& Metabolism 25 143-151. (doi:10.1016/j.beem.2010.08.015)

Received in final form 11 March 2015

Accepted 1 April 2015 